\title{
Los suboficiales practicantes y ayudantes técnicos de Sanidad Militar en el Ejército (1945 -1989)
}

\author{
Naranjo García JF. ${ }^{1}$
}

Sanid. mil. 2014; 70 (3): 215-217; ISSN: 1887-8571

\begin{abstract}
RESUMEN
Introducción: Los actuales oficiales Enfermeros que nacieron con la ley 39/2007 son los herederos de unos profesionales sanitarios de la milicia que, aunque tan antiguos como la propia guerra, comenzaron su andadura militar en 1945 fruto de un gran legado histórico y desarrollaron hasta el año 1989 un trabajo callado dentro del Cuerpo de Suboficiales del Ejército. Cambiaron de nombre pero no de trabajo, siempre auxiliares de los cuadros médicos de las Unidades y de los Hospitales Militares. Esta es su pequeña Historia. Método: Historiográfico. Fuentes: Principalmente legislativas y asentadas sobre una bibliografía básica (tesis y monografías). Conclusiones: Se observa como los avances en materia educativa de la profesión civil ha influido en el resultado final de la Escala Militar.
\end{abstract}

PALABRAS CLAVE: Practicante, Enfermero, Ayudante Técnico Sanitario, Militar.

\section{Practitioners non-commissioned officer and technical assistants in the Army Military Health}

SUMMARY: Introduction: The modern day officers of the Nurse Corp were born of the 39/2007 law, making them the heirs of militia sanitary professionals. While as old as war itself, they only began consolidating their military career in 1945; fruit of a great historical legacy which then continued to develop their behind the scenes role in the NCOs Corp up until 1989. While their name may have changed, their job has not; that of auxiliary medical personnel attached to units and military hospitals. This is their small story. Method: historiography. Sources: Primarily legislative and settled on a basic literature (theses and monographs). Conclusions: It is seen as progress in education civil profession has influenced the outcome of the military range.

KEY WORDS: Practitioner, Nurse, Sanitary technician, Military.

\section{ORIGEN Y DENOMINACIÓN}

Nuestra Historia empieza en 1945, cuando el Ejército creó el Cuerpo Auxiliar de Practicantes de Sanidad Militar ${ }^{1}$. Pero los entrañables practicantes ya venían de antiguo en el Ejército aunque no fue hasta la finalización de la Guarra Civil cuando se les comenzó a considerar militares, con los mismos derechos que el resto. A través de la Historia, los que hoy se denominan diplomados universitarios en enfermería (DUE), han sido conocidos de diferentes maneras, dependiendo de las costumbres o de los estudios académicos exigidos. Conforme se suceden importantes avances en los conocimientos sanitarios, comienzan a dibujarse en el s. XIX nuevos campos y especializaciones clínicas en las que aparece la figura del ministrante, término que no gusta a la clase médica, que prefiere la denominación de practicante, sinónimo de estudiante de medicina en prácticas, para definir a los que realizaban cirugía menor ${ }^{2}$.

Los practicantes componían un grupo intermedio entre los médicos y los enfermeros, cuyo solo nombre sugería provisionalidad, transitoriedad en su preparación. Se sanciona con la publicación de la ley de Instrucción Pública de 1857, en la que se regula la carrera de practicante, desapareciendo la cirugía menor y los ministrantes ${ }^{3}$.

Tte Transmisiones (Reserva). Licenciado en Historia.

Dirección para correspondencia: jnargar@gmail.com

Recibido: 16 de julio de 2013

Aceptado: 29 de abril de 2014
El correspondiente reglamento, que se publicó en 1861, establecía un periodo de formación de cuatro semestres en hospitales públicos, debiendo superar previamente un examen de acceso en el que tenían que demostrar conocimientos elementales de medicina, anatomía y curas ${ }^{4}$. Por ello la segunda mitad del s. XIX fue trascendental para los practicantes que ejercían su profesión en la vida civil, al exigirles una formación ya reglada. ¿Pero qué pasaba con los practicantes de la Sanidad Militar?

En el Ejército no se comenzó a contemplar la posibilidad de que los practicantes fueran titulados, a diferencia de la Armada que desde 1860 así lo obligaba, hasta la publicación del reglamento de reclutamiento de 1925 en el que se preveía que los mozos con la titulación de practicantes realizarían el servicio militar precisamente en unidades de Sanidad Militar ${ }^{5}$.

\section{RECLUTAMIENTO}

El origen del personal componente del Cuerpo Auxiliar de Practicantes de Sanidad Militar a partir de 1945 era:

- Primero, el personal del extinto Cuerpo de Practicantes de Medicina de Sanidad Militar, que no se integraron en el Cuerpo Auxiliar de Subalternos del Ejército (CASE). Ninguno de los dos Cuerpos estaba compuesto por personal militar.

- Segundo, los practicantes del CASE que voluntariamente lo solicitaran, y que pertenecían a la cuarta Subsección de la Segunda Sección. 
- Tercero, el personal masculino con el título de practicante en medicina y cirugía, que se encontrara prestando servicio de cualquier clase en el Ejército y Guardia Civil1 ${ }^{(1)}$.

- Cuarto, el personal civil, en posesión del título correspondiente, que prestaba servicio en cualquier dependencia del Ejército.

El personal de los dos últimos puntos debía someterse a un concurso-oposición. Una vez agotado el personal de los puntos arriba señalado, el reclutamiento se realizaba entre el personal militar y civil con la titulación de practicante en medicina y cirugía. Por tanto, dos características sobresalían en el reclutamiento de la Escala Auxiliar de Practicantes:

- En primer lugar, y la más importante, la exigencia del título sanitario correspondiente.

- En segundo lugar, la modalidad de oposición para el ingreso tanto entre militares como civiles.

Recordamos que estas condiciones únicamente se aplicaban en el Ejército al personal de los Cuerpos más especializados: jurídicos, médicos, veterinarios y farmacéuticos y a los suboficiales miembros del Cuerpo Auxiliar de Practicantes de Farmacia reglados casi al mismo tiempo ${ }^{6}$.

En 1947 se publicó la primera convocatoria para la oposición de los grupos de tropa y personal civil contemplándose la obligatoriedad de la posesión del título oficial de practicante? Las pruebas, de gran dureza, pero acorde con las exigidas para las demás oposiciones del Estado que se realizaban en la época, tenían cuatro partes:

- Reconocimiento médico

- Desarrollo oral de un tema de anatomía, fisiología e higiene; otro de material médico y medicaciones y, por último, un tercero sobre materia quirúrgica, disponiendo de un máximo de diez minutos para cada uno.

- Desarrollo de un tema de los expuestos en el programa de la oposición, con un tiempo de dos horas.

- Por último, desarrollo práctico de uno de los temas del programa, con un tiempo de diez minutos.

Los temas elegidos lo serían por sorteo. La primera prueba era calificada como "apto" o "no apto", el resto mediante notas numéricas. Todas las pruebas eran eliminatorias siendo obligatorio sacar al menos un cinco en cada una de ellas estableciéndose coeficientes de ponderación para hallar la nota final de cada opositor.

Las pruebas de acceso se realizaron siempre en la Academia de Sanidad que, por imperativos académicos, cambió su denominación en 1972, sin que se modificaran las modalidades de reclutamiento ${ }^{8}$

\section{FORMACIÓN}

Los que obtenían plaza en las pruebas de acceso, ingresaban en la Academia de Sanidad Militar con el título de practicantesalumnos, para realizar un curso de capacitación profesional y de conocimientos militares de una duración de cuatro meses, en

\footnotetext{
(1) Durante la Guerra Civil, había personal femenino entre los practicantes de Medicina Militar pero el Ejército no contempló la posibilidad de su integración en el nuevo Cuerpo.
}

régimen de internado, que era el método estándar utilizado en la época para la formación de los militares.

Los que lo superaran, eran promovidos a la categoría de practicantes de segunda, asimilados a brigadas. El ascenso a practicantes de primera, lo harían por antigüedad(2).

La Academia de Sanidad Militar se creó en 1877 y se cerró en 1880. Se volvió a inaugurar en 1895 con el nombre de Academia Medico-Militar y en 1918 tomó su antiguo nombre ${ }^{(3)}$. En cuanto a su ubicación pasó por diversas zonas de la capital: calles Rosales, Altamirano y Quinta, cuartel del Conde-Duque y Chamartín de la Rosa. Actualmente se encuentra en Carabanchel Bajo, junto al Hospital Militar Central "Gómez Ulla"9. En 1988 cambió su denominación por la de Academia de Asistencia Sanitaria y el 1992 por la de Escuela Militar de Sanidad.

En 1975 se fusionaron la Escuela de Aplicación de Sanidad Militar, creada en 1959, y la Academia de Sanidad Militar, como había sucedido con el resto de las Escuelas de Aplicación y Tiro de las armas y cuerpos del Ejército ${ }^{10}$.

Los métodos y el lugar de formación cambiaron drásticamente cuando en 1976 se convocó la oposición para cubrir las plazas de la XXIII promoción ${ }^{11}$. En la orden de los que aprobaron la oposición se especificó que los alumnos debían efectuar su presentación en la Academia General Básica de Suboficiales (AGBS) en Tremp (Lérida) para desarrollar el periodo de formación de las materias comunes y militares.

La primera fase del curso tenía una duración aproximada de tres meses orientado a la preparación integral, con cuatro áreas de formación:

- Capacitación militar.- Instrucción de combate y táctica.

- Preparación científico-técnica.- Topografía

- Humanística.- Reales Ordenanzas, ética, justicia militar y escritos militares

- Educación física.- Una hora diaria de gimnasia.

La primera parte de la formación iba dirigida a que tuvieran conciencia de su condición de suboficiales, de los fines de la Defensa Nacional y a la ética específicamente militar. La segunda, mucho más definida para su titulación, se realizaba en la Academia de Sanidad Militar, con una duración de tres meses más.

El año 1977 fue decisivo para la Historia de los ATS en general y para los militares en particular ya que las Escuelas de Ayudantes Técnicos Sanitarios que existían en las Facultades de Medicina se convirtieron en Escuelas Universitarias de Enfermería, integradas en la Universidad, es decir, que los estudios de ATS se convirtieron en carrera universitaria ${ }^{12}$. Por tanto nuestros ATSM eran universitarios, los primeros suboficiales con título universitario.

Por la AGBS pasaron catorce promociones (desde la XXIII a la XXXVI) que lucieron las cadeteras blancas sobre sus uniformes y con la denominación de caballeros alumnos ${ }^{13}$. Un hito importante tanto para los ATSM como para la AGBS fue que, por primera vez en la Historia, la mujer hacía acto de presencia como

\footnotetext{
(2) En aquella época, el Cuerpo de Suboficiales del Ejército estaba compuesto por los empleos de sargento y brigada.

(3) La Academia de Sanidad Militar se creó por real orden de 20 de mayo de 1877. Colección Legislativa del Ejército (CLE) n. ${ }^{\circ} 189$. Tomó el nombre de Academia de Sanidad Militar por real orden circular 14 de noviembre de 1918. CLE n. ${ }^{\circ}$ 307. Por último se creó la actual Escuela Militar de Sanidad por real decreto 46 de 24 de enero1992. BOE n 30.
} 
militar con todos los derechos y fue en 1988 con la XXXV promoción en la que nueve diplomadas ingresaron por primera vez en una academia militar, y alcanzaron un empleo militar en $1989^{14}$.

\section{MODELO DE CARRERA}

Superado el plan de estudios alcanzaban un estatus profesional idéntico al que disfrutaba el resto del personal de las armas y cuerpos del Ejército, es decir, uniforme e insignias correspondientes a su empleo, gratificaciones, condecoraciones, premios de permanencia, las mismas situaciones militares y demás beneficios de toda índole.

Los empleos durante el tiempo que pervivió la ley de 1945 eran:

- Practicantes de primera, con asimilación de teniente

- Practicantes de segunda, con asimilación de brigada

Los ascensos se producían por antigüedad y con ocasión de vacante sin que fuera necesario superar ningún curso. En 1960 se crearon dos nuevos empleos en el Cuerpo de Suboficiales: sargento primero y subteniente ${ }^{15}$. Fue aplicado al Cuerpo de practicantes en 1965 y sólo le afectó uno de ellos, el de subteniente ${ }^{16}$. Para el ascenso a subteniente era necesario tener al menos diez años de antigüedad en el empleo de brigada, lo que sin duda perjudicó de manera ostensible las perspectivas de mejora social y económica de los practicantes. Pero para el ascenso a practicantes de primera, se eximió del plazo de mínima permanencia en el empleo de subteniente.

Con la ley de reorganización de 1972 se ampliaron a cuatro los empleos militares de los ATSM, aunque para los suboficiales solo supuso un cambio en la categoría, bajando de segunda a tercera:

- ATSM mayor, asimilado a comandante

- ATSM de primera, asimilado a capitán

- ATSM de segunda, asimilado a teniente

- ATSM de tercera, asimilado a brigada o subteniente, dependiendo de la antigüedad en el Servicio.

Las vacantes de los ATSM de tercera y segunda serían cubiertas indistintamente, lo que suponía que cuando ascendieran no perderían el destino ${ }^{17}$.

En relación con las edades de retiro forzoso, la ley de 1972 respetó lo dispuesto en 1945 que las había fijado en los sesenta años de edad, a excepción de los procedentes del CASE y del Cuerpo de Practicantes de Medicina y Cirugía que conservaban los derechos adquiridos en sus respectivas escalas de origen, así como las asimilaciones, consideraciones, sueldos, quinquenios, etc.

La ley reguladora del régimen del personal militar profesional de 1989 significó un punto de inflexión para todos los militares, y muy especialmente para los ATSM. Nuestros practicantes dejaron de pertenecer a la categoría de suboficiales y pasaron a engrosar las filas de los oficiales de la Escala Media, desde el empleo de alférez, como titulados universitarios que eran. Por ello dejaron de asistir al curso que se había impartido en la AGBS desde 1976 al mismo tiempo que perdieron la exclusividad de su pertenencia al Ejército, al unificarse en una única escala todos los ATSM del Ministerio de Defensa, en los denominados Cuerpos Comunes ${ }^{18}$.

Pero eso ya es otra Historia. Aquella ley puso punto y final a 54 años de convivencia de los practicantes y ATS entre los suboficiales del Ejército. Durante aquel periodo de tiempo alcanzaron grandes cotas de profesionalidad. Estuvieron presentes en los cuarteles, paliando el dolor de los soldados, mandos y sus familias, auxiliaron a los médicos en su trabajo diario, en maniobras y ejercicios y compartiendo las fatigas con el resto de los compañeros.

Participaron en tres expediciones como Misión Sanitaria Española a Vietnam del Sur durante el conflicto en aquella parte del mundo. En el conflicto del Sáhara fueron justos protagonistas. Y resultaron imprescindibles desde las primeras misiones humanitarias en las que participó el Ejército fuera de nuestras fronteras.

Sirvan estas líneas como homenaje de reconocimiento a aquellos suboficiales por su labor brillante y callada.

\section{BIBLIOGRAFÍA}

1. Ley de 17 de marzo de 1945, creando el Cuerpo Auxiliar de Practicantes de Sanidad Militar. BOE n. ${ }^{\circ} 78$.

2. Jiménez Rodríguez, I. Las titulaciones quirúrgico-médicas a mediados del siglo XIX: los ministrantes, Cultura de los Cuidados. Revista de Enfermería y Humanidades n ${ }^{\circ}$ 19, Universidad de Alicante 2006: 1-21.

3. Ley de 9 de septiembre de 1857, de instrucción pública. Gaceta de Madrid (GM) n ${ }^{\circ} 1710$.

4. Reglamento de 21 de noviembre de1861, para la enseñanza de Practicantes y Matronas. $\mathrm{GM} \mathrm{n}^{\circ} 332$.

5. Real decreto de 27 de febrero de 1925 , desarrollo del real decreto ley de bases de 29 de marzo de 1924, relativa al reclutamiento y reemplazos del Ejército. GM n. ${ }^{\circ} 65$. Artículo 356.

6. Ley de 17 de julio de 1945, por la que se crea el Cuerpo Auxiliar de Practicantes de Farmacia Militar. BOD n. ${ }^{\circ} 202$.

7. Orden de 16 de julio de 1947, por la que se convoca oposición para el ingreso en el Cuerpo Auxiliar de Practicantes de Sanidad Militar. Diario Oficial del Ejército (DOE) n. ${ }^{\circ} 162$.

8. Ley de 19 de 10 de mayo de 1972, por la que se reorganiza el Cuerpo Auxiliar de Practicantes de Sanidad Militar. BOD n 113 . A partir de aquella ley el Cuerpo pasó a denominarse Auxiliar de Ayudantes Técnicos de Sanidad Militar, ATSM.

9. Fernández Maldonado, E. Retazos de una Historia. Tremp, 1999: 139.

10. Decreto 1647, de 23 de septiembre de 1959, por el que se crea la Escuela de Aplicación de Sanidad Militar. BOE n. ${ }^{\circ} 231$. Orden de 28 de noviembre de 1975, por la que se fusionan en Madrid la Escuela de Aplicación de Sanidad Militar y la Academia de Sanidad Militar. DOE n. ${ }^{\circ} 271$.

11. Orden de 23 de abril de 1976, por la que se convoca el concurso-oposición para cubrir plazas del Cuerpo Auxiliar de Sanidad Militar. DOE n. 106.

12. Real decreto 2128 , de 23 de julio de 1977, sobre integración en la Universidad de las Escuelas de Ayudantes Técnicos Sanitarios como Escuelas Universitarias de Enfermería. BOE n. ${ }^{\circ} 200$.

13. Un total de 278 alumnos y alumnas de los que 274 finalizaron con éxito el curso.

14. Real decreto-ley 1, de 22 de febrero de 1988, por el que se regula la incorporación de la mujer a las Fuerzas Armadas. La XXXV promoción de ATSM fueron nombrados alumnos por resolución 432/38786/88. BOD n. ${ }^{\circ} 159$ y fueron ascendidos a Ayudantes Técnicos de Sanidad Militar de Tercera, asimilados a brigada, por resolución 562/04597/89. BOD n. ${ }^{\circ} 51$.

15. Ley 46, de 21 de julio de 1960, por la que se crean dos nuevas categorías en el Cuerpo de Suboficiales del Ejército. BOE n. ${ }^{\circ} 176$.

16. Orden de 14 de mayo de 1965, por el que se aplica al Cuerpos de Auxiliares de sanidad Militar las categorías militares de la ley 46 de 21 de julio de 1960. DOE n. ${ }^{\circ} 112$.

17. Orden de 30 de junio de 1972 , de desarrollo de la ley 19/1972 por la que se reorganiza el Cuerpo de Auxiliar de Practicantes de Sanidad Militar. BOE n. ${ }^{\circ} 166$.

18. Ley 17, de 19 de julio de 1989, Reguladora del Régimen del Personal Militar Profesional. BOE n. ${ }^{\circ}$ 172. Punto 2, artículo 29. 